\title{
Study of the diffraction pattern of cloud particles and the respective responses of optical array probes
}

\author{
Thibault Vaillant de Guélis ${ }^{1}$, Alfons Schwarzenböck ${ }^{1}$, Valery Shcherbakov ${ }^{1,2}$, Christophe Gourbeyre $^{1}$, \\ Bastien Laurent $^{1}$, Régis Dupuy ${ }^{1}$, Pierre Coutris ${ }^{1}$, and Christophe Duroure ${ }^{1}$ \\ ${ }^{1}$ Université Clermont Auvergne, CNRS, UMR 6016, Laboratoire de Météorologie Physique, \\ Clermont-Ferrand, France \\ ${ }^{2}$ Université Clermont Auvergne, Institut Universitaire de Technologie d'Allier, Montluçon, France
}

Correspondence: Thibault Vaillant de Guélis (t.vaillant-de-guelis@opgc.fr)

Received: 13 December 2018 - Discussion started: 20 December 2018

Revised: 20 March 2019 - Accepted: 1 April 2019 - Published: 26 April 2019

\begin{abstract}
Optical array probes (OAPs) are classical instrumental means to derive shape, size, and number concentration of cloud and precipitation particles from 2-D images. However, recorded 2-D images are subject to distortion based on the diffraction of light when particles are imaged out of the object plane of the optical device. This phenomenon highly affects retrievals of microphysical properties of cloud particles. Previous studies of this effect mainly focused on spherical droplets. In this study we propose a theoretical method to compute diffraction patterns of all kinds of cloud particle shapes in order to simulate the response recorded by an OAP. To check the validity of this method, a series of experimental measurements have been performed with a 2D-S probe mounted on a test bench. Measurements are performed using spinning glass discs with imprinted noncircular opaque particle shapes.
\end{abstract}

\section{Introduction}

In Earth's atmosphere, the evolution of clouds is highly dependent on interactions of a number of dynamical, radiative, and microphysical processes (Boucher et al., 2013). Actual knowledge of cloud microphysical properties is mainly due to in situ measurements with airborne instrumentation (Baumgardner et al., 2017). Therein, optical array probes (OAPs; Knollenberg, 1970) are classical instrumental means to measure the shape, concentration, and number size distribution of cloud and precipitation particles. OAP probes are based on the principle of a linear array of photodetectors illu- minated by a laser to image cloud particles crossing the laser beam. However, these probes are subject to several uncertainties. Indeed, the particle size is derived from a 2-D projection of a 3-D particle which is either arbitrarily oriented in 3-D space or has a preferential orientation in the cloud (e.g., Cho et al., 1981; Noel and Sassen, 2005) and/or due to the air flow around the aircraft fuselage (King, 1986). Moreover, the 2-D image is subject to distortion due to the diffraction effect of light when cloud particles are imaged out of the object plane of the optical device (e.g., Thompson, 1964). The latter phenomenon highly affects smaller cloud particles up to several hundred micrometers in particle diameter. What is more, the exact quantification of smaller cloud particle properties is essential for cloud radiative effects, precipitation, lightning, and flight safety studies (Lawson et al., 1998; Mason et al., 2006; Mitchell et al., 2008; McFarquhar et al., 2017b). Moreover, the significant uncertainties of retrieved particle size distributions for smaller particles (Baumgardner et al., 2017) preclude confirmation or rejection of theories on secondary ice production. Indeed, relatively high concentrations of small ice particles $(<100 \mu \mathrm{m})$ are found in clouds even after careful OAP image processing (e.g., Field et al., 2006; Korolev and Field, 2015), which aims to remove small particle fragments produced by shattering of larger ice crystals impacting on probe surfaces (e.g., Gardiner and Hallett, 1985; Korolev and Isaac, 2005; Korolev et al., 2011; Field et al., 2017). Furthermore, common OAP image processing algorithms include items such as the reconstruction of truncated images (Korolev and Sussman, 2000), elimination of noisy pixels (Lawson, 2011) and splashing (Baker et al., 
2009), consideration of overload times in the sample volume computation (McFarquhar et al., 2017a), and identification of particle coincidence in clouds with a high number of concentrations of crystals. Despite these improvements in OAP image processing, numerous in situ measurements demonstrated that the concentrations of ice nuclei are much lower than crystal concentrations (e.g., Mossop, 1968; Cantrell and Heymsfield, 2005; DeMott et al., 2016; Field et al., 2017). Secondary ice production theories (e.g., Koenig, 1965; Hallett and Mossop, 1974; Takahashi et al., 1995; Bacon et al., 1998; Leisner et al., 2014) are necessary to explain these high concentrations of small ice particles. Quantifying the uncertainty in OAP records due to diffraction is therefore another important contribution for a better understanding of those processes.

Diffraction patterns of spherical water droplets recorded by OAPs, using laser wavelengths that are small compared to droplet sizes, have been thoroughly studied theoretically and experimentally (e.g., Hovenac et al., 1985; Joe and List, 1987; Hirleman et al., 1988; Korolev et al., 1998; Korolev, 2007). Good agreement between theory and experimental studies has been found for the diffraction patterns produced by opaque discs (e.g., Hovenac, 1986; Korolev et al., 1991). By contrast, diffraction patterns have not been extensively studied concerning non-spherical particle shapes, i.e., ice cloud particles (e.g., Connolly et al., 2007; Gurganus and Lawson, 2018). Arising questions are the following. How does the diffraction impact retrieved particle sizes of 2-D images that result from projection of 3-D crystals? Do we observe a bright spot in the center of the 2-D images as commonly observed for spherical particles? Is the real shape of the cloud particle always recognizable from the diffracted 2D image?

In this study, we propose a theoretical method to compute diffraction patterns of all kinds of cloud particle shapes. The validity of the method is checked with a series of measurements using one of the newest OAPs - the two-dimensional stereo (2D-S) probe (Lawson et al., 2006) - mounted on a test bench. Non-circular opaque particle shapes, e.g., columns and capped columns, differing in size and orientation have been printed on spinning glass discs, as was performed first by Hovenac (1986) for disc shapes only.

In Sect. 2, we briefly present the simulations of the implemented diffraction theory, define the utilized terms of in-focus, out-of-focus, and out-of-DoF (depth of field), and present the experimental device consisting of a 2D-S probe combined with a spinning disc with imprinted opaque particle shapes. In Sect. 3, we compare results obtained theoretically by diffraction simulations and experimentally with spinning discs and the 2D-S on the test bench.

\section{Method}

\subsection{Simulations}

When light (a laser beam for OAPs) illuminates a cloud particle, a shadow image can be observed on a screen at the rear of the particle. The formed image depends on the diffraction, refraction, and transmission of light by the particle. As a first approximation, it is convenient to neglect the refraction and transmission of light by the particle, i.e., considering the cloud particle as an opaque particle. It should be noted that ice particles which allow significant light transmission will have additional sources of error that are not captured in this experiment. A further assumption is that the diffraction pattern produced by an opaque particle is accurately described by the diffraction pattern produced by an opaque planar object representing the cross section of the particle. Laboratory studies showed that these approximations work well for outof-focus transparent spherical particles (e.g., Hovenac, 1986; Korolev et al., 1991). For this study, we assume that it is also true for ice cloud particles.

The diffraction pattern of an opaque planar shape can be computed with different theoretical methods. Korolev et al. (1991) computed the diffraction pattern of an opaque disc using the Maggi-Rubinowicz representation of the HelmholtzKirchhoff diffraction integral (Miyamoto and Wolf, 1962). Also, the Maggi-Rubinowicz method (MRM) can be adapted to other planar shapes. At the same time, the method is quite time-consuming and the analytical parameterization of the non-circular particle contour needs to be developed for each shape. In this study, we employed the method proposed in Vaillant de Guélis et al. (2019), which is based on angular spectrum theory (AST; see Appendix A). Despite the apparent differences, "the angular spectrum approach and the first Rayleigh-Sommerfeld solution yield identical predictions of diffracted fields" (Goodman, 1996, p. 61). Recall that the Helmholtz-Kirchhoff diffraction integral and the RayleighSommerfeld formula can be considered different formulations of the general scalar diffraction theory (e.g., Goodman, 1996; Ersoy, 2007). Note also that the validity region of Rayleigh-Sommerfeld solutions includes the Fresnel approximation and the Fraunhofer approximation regions of validity (e.g., Gaskill, 1978, p. 362).

Fast Fourier transform (FFT) can be utilized for the numerical implementation of the AST. Also, FFT-based algorithms are easy to implement and effective. That is why the AST is extensively employed in different domains, including simulations of diffraction patterns (e.g., Matsushima et al., 2003; Matsushima and Shimobaba, 2009). According to our computations, the AST-FFT modeling is several orders of magnitude faster than MRM-based calculations. AST-FFT modeling needs as input information a binary matrix representing the opaque shape of the particle and its location within the optical path. The latter is defined by the distance $Z$ from the particle to the position at which we want to compute the 


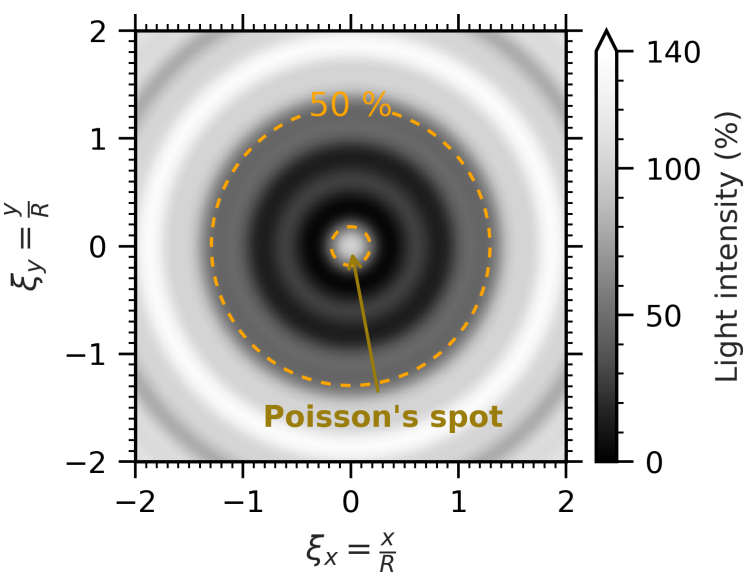

Figure 1. Theoretical diffraction pattern simulated for an opaque disc with diameter $D=2 R$ at dimensionless distance $Z_{\mathrm{d}}=$ $Z \lambda / R^{2}=1.0$. The orange dashed line represents the $50 \%$ intensity threshold. Due to diffraction, a bright spot - called Poisson's spot - appears at the center of the shadow diffraction pattern.

diffraction pattern or the distance from the object plane to the particle when using an optical system. We performed numerical simulations of diffraction patterns recorded by a binary OAP probe, which in this study corresponds to a $2 \mathrm{D}-\mathrm{S}$ probe described in Sect. 2.2.

As noted by Korolev et al. (1991), the diffraction pattern by an opaque disc can be presented as a function of only one dimensionless variable $Z_{\mathrm{d}}=\frac{\lambda Z}{R^{2}}$, with $\lambda$ the wavelength and $R$ the radius of the disc. Note that $Z_{\mathrm{d}}=\frac{1}{N_{\mathrm{F}}}$ is the inverse of the well-known Fresnel number $N_{\mathrm{F}}$. Figure 1 shows the diffraction pattern by an opaque disc at a specific distance $Z_{\mathrm{d}}=1.0$. Figure axes $\xi_{x}$ and $\xi_{y}$ are coordinates normalized by $R$.

We notice that a bright spot, called Poisson's spot, appears at the center of the diffraction pattern shadow image. The orange dashed line represents the $50 \%$ intensity threshold generally applied in binary (monoscale) OAP probes. For this specific case, it can be seen that an OAP operating with this threshold will produce a "donut" image with an external diameter that exceeds by $30 \%$ the true disc diameter.

Figure 2, calculated in analogy to Fig. 2 of Korolev et al. (1998), shows the light intensity along a radius of the diffraction pattern produced by an opaque disc with a normalized radial coordinate $\xi=\frac{r}{R}$ as a function of $Z_{\mathrm{d}}$.

With increasing distance $Z_{\mathrm{d}}$ from the object plane (where $Z_{\mathrm{d}}=0$ ), the opaque disc is more and more out-of-focus and the diffraction pattern shows a Poisson spot which continuously increases and an external diameter which generally increases with $Z_{\mathrm{d}}$, albeit with small oscillations for $Z_{\mathrm{d}}<2$. From $Z_{\mathrm{d}}=0.15$ the disc shadow can appear with a magnification greater than $110 \%$. This arbitrary limit (Knollenberg, 1970) defines the separation of in-focus from out-of-focus images. As $Z_{\mathrm{d}}$ continues to increase, the diffraction pattern

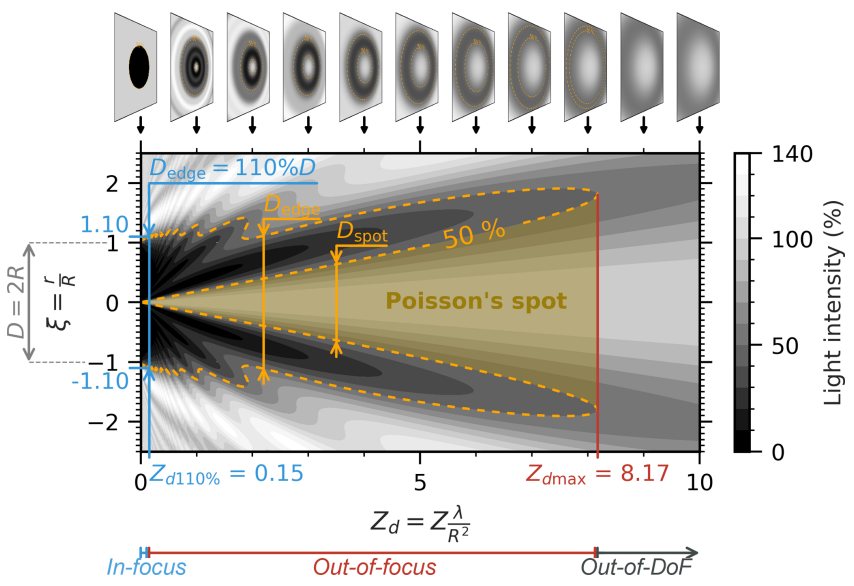

Figure 2. Intensity level of the diffraction pattern of an opaque disc in $Z_{\mathrm{d}}-\xi$ coordinates: the intensity profile along the $\xi$ axis at a specific $Z_{\mathrm{d}}$ represents the intensity profile along a section of the diffraction pattern of an opaque disc at a distance $Z_{\mathrm{d}}$ (see the diffraction pattern for $Z_{\mathrm{d}}=1.0$ in Fig. 1). As $Z_{\mathrm{d}}$ increases, the image becomes less focused and the diameter of the Poisson spot increases. At the $50 \%$ intensity triggering level, the external diameter of the diffraction pattern of the disc shadow can appear with magnification greater than $110 \%$ from $Z_{\mathrm{d}}=0.15$, which we define as the arbitrary limit of an in-focus image, and the disc shadow totally disappears beyond $Z_{\mathrm{d}}=8.17$.

becomes more and more blurry, and at some point the light intensity no longer falls below a specific triggering level at any point of the pattern. This means for a $50 \%$ intensity triggering level of a binary OAP probe that the disc shadow totally disappears beyond $Z_{\mathrm{d} \max }=8.17$ (Korolev et al., 1998). This distance delimits the region of the depth of field (DoF) of the particle (Korolev et al., 1991). Beyond this limit, a particle is out-of-DoF and is no longer recorded on a $50 \%$ intensity triggering level instrument. As $Z_{\max }=R^{2} Z_{\mathrm{d} \max } / \lambda$, the DoF increases with the square of the particle size and the inverse of the wavelength.

\subsection{Experimental device}

The two-dimensional stereo (2D-S) probe (Lawson et al., 2006) is an OAP that records the diffraction pattern of particles illuminated by a laser beam with wavelength $\lambda=$ $783 \mathrm{~nm}$ on a 128-photodiode array. As a particle crosses the laser beam of the instrument, slices of 128 pixels are recorded one after another at a specific frequency which is chosen such that the pixel size in the direction of the moving particle is $10 \mu \mathrm{m}$. The size of the pixels in the array direction can slightly vary from one instrument to another. Based on our own calibration using a spinning glass disc with imprinted opaque disc shapes (described further below), we found a mean value of $11.4 \mu \mathrm{m}$ for the pixel size parallel to the array for the 2D-S used in this study. Note that the 2D-S has been sent to the SPEC Inc. company for a complete check prior to 
(a)

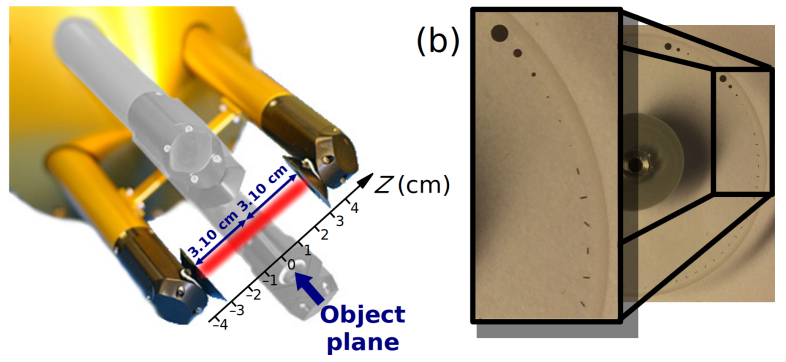

Figure 3. (a) $2 \mathrm{D}-\mathrm{S}$ probe with a schematic of the laser beam. The probe consists of two pairs of arms allowing measurements in two orthogonal directions. We only consider one couple of arms here. The object plane is located in the middle of the laser beam between the two arms. (b) Spinning disc with imprinted opaque particle shapes.

the tests for this study. Images recorded are monochromatic images based on a $50 \%$ intensity triggering level. The transmitting optics consist of a single-mode fiber-coupled diode laser and beam shaping optics (Lawson et al., 2006). Thus, we can assume that a particle is illuminated by a monochromatic plane wave. The receiving system consists of imaging optics and a linear photodiode array. The imaging optical system is based on a Keplerian telescope design. The photodiode array is positioned in the focal plane of the back lens (the eyepiece) in the image space. The object plane is the conjugate plane, that is, the focal plane of the front lens (the objective) in the object space. Based on the instrument optics, the object plane is located in the middle of the laser beam between the two arms of the probe (Fig. 3a).

Therefore, distance $Z$ discussed in the previous section corresponds to the distance of the particle to the object plane (located at $Z=0$ ). The diffraction image of a particle crossing the laser beam at $Z=x$ is identical to the diffraction image produced by a particle crossing the laser beam at $Z=-x$.

Considering opaque discs crossing the 2D-S laser beam, Fig. 4 shows the evolution of the DoF limit $Z_{\max }$ and the infocus limit $Z_{110} \%$ as a function of the variable opaque disc diameter $D$.

A particle with $D=500 \mu \mathrm{m}$ is seen in-focus, i.e., $D_{\text {edge }}<$ $110 \% D$, as long as the distance of the particle to the object plane is $Z<1.2 \mathrm{~cm}$. From $Z=1.2$ to $Z=3.1 \mathrm{~cm}$ (arm limit), the particle is out-of-focus; i.e., the particle is still detected (at least one photodiode triggered), but its image is progressively deformed due to diffraction. For a particle with $D=50 \mu \mathrm{m}$, the in-focus zone is very small $\left(Z_{110 \%}=\right.$ $0.01 \mathrm{~cm}$ ) and the particle is no longer detected beyond $Z_{\max }=0.65 \mathrm{~cm}$. Particles larger than $109 \mu \mathrm{m}$ should be always seen by the $2 \mathrm{D}-\mathrm{S}$ since the $\mathrm{DoF}$ is starting to exceed the distance between the probe arms $(6.2 \mathrm{~cm})$. However, particles of that size are potentially observed with more or less important distortion in the out-of-focus domain. Particles larger than $806 \mu \mathrm{m}$ should be imaged by the 2D-S without impor-

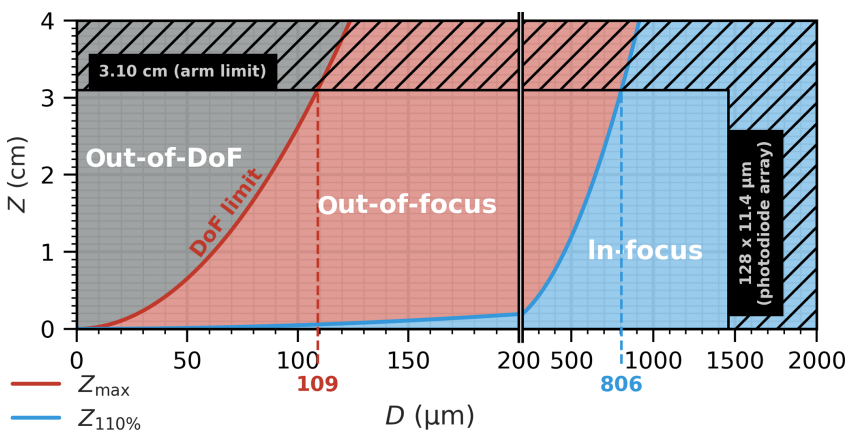

Figure 4. Depth of field (DoF) limit (distance $Z_{\max }$ from the object plane) separating out-of-DoF and out-of-focus regions, and in-focus limit (distance $Z_{110 \%}$ from the object plane where the external diameter of the diffraction pattern appears with $110 \%$ magnification) separating out-of-focus and in-focus regions, for an opaque disc with diameter $D$ measured with the two-dimensional stereo (2DS) probe. The hatched area illustrates the arm limit and the 128photodiode array size.

tant distortion, since $Z_{110 \%}>3.1 \mathrm{~cm}$ for sizes larger than $806 \mu \mathrm{m}$.

In the following third section, we compare theoretical diffraction patterns of different opaque shapes with experimental measurements of the 2D-S probe. Therefore, several spinning glass discs with various chrome opaque particle shapes imprinted on the glass disc surfaces were used (Fig. 3b). This has been performed for opaque disc shapes in the past (e.g., Hovenac and Hirleman, 1991; Reuter and Bakan, 1998) and most recently also for plate and rosette-type particles (Gurganus and Lawson, 2018). Here we present results for two opaque planar particle shapes: rectangle-type shapes which represent the cross section of a columnar particle and " $H$ "-type shapes which represent the cross section of a capped columnar particle. Particle shapes were imprinted with three different orientations: 0,45 , and $90^{\circ}$. Note that the chosen shapes represent only one particular projection of a 3-D particle (columnar or capped columnar particles) on a 2-D plane.

\section{Results}

\subsection{Comparison of theoretical images with measurements}

Figure 5 shows results for a $1: 2$ (width : height) short columnar particle with four different sizes (the well-known results for opaque discs are reported in Appendix B).

In each column, on the left-hand side are shown the theoretical 2D-S records and on the right-hand side are shown the images recorded by the 2D-S experimentally. The theoretical 2D-S records are obtained by AST-FFT simulations (Sect. 2.1) with a modeling resolution of $1 \mu \mathrm{m}$, $50 \%$ intensity threshold, and subsequently $10 \times 11.4 \mu \mathrm{m}$ 


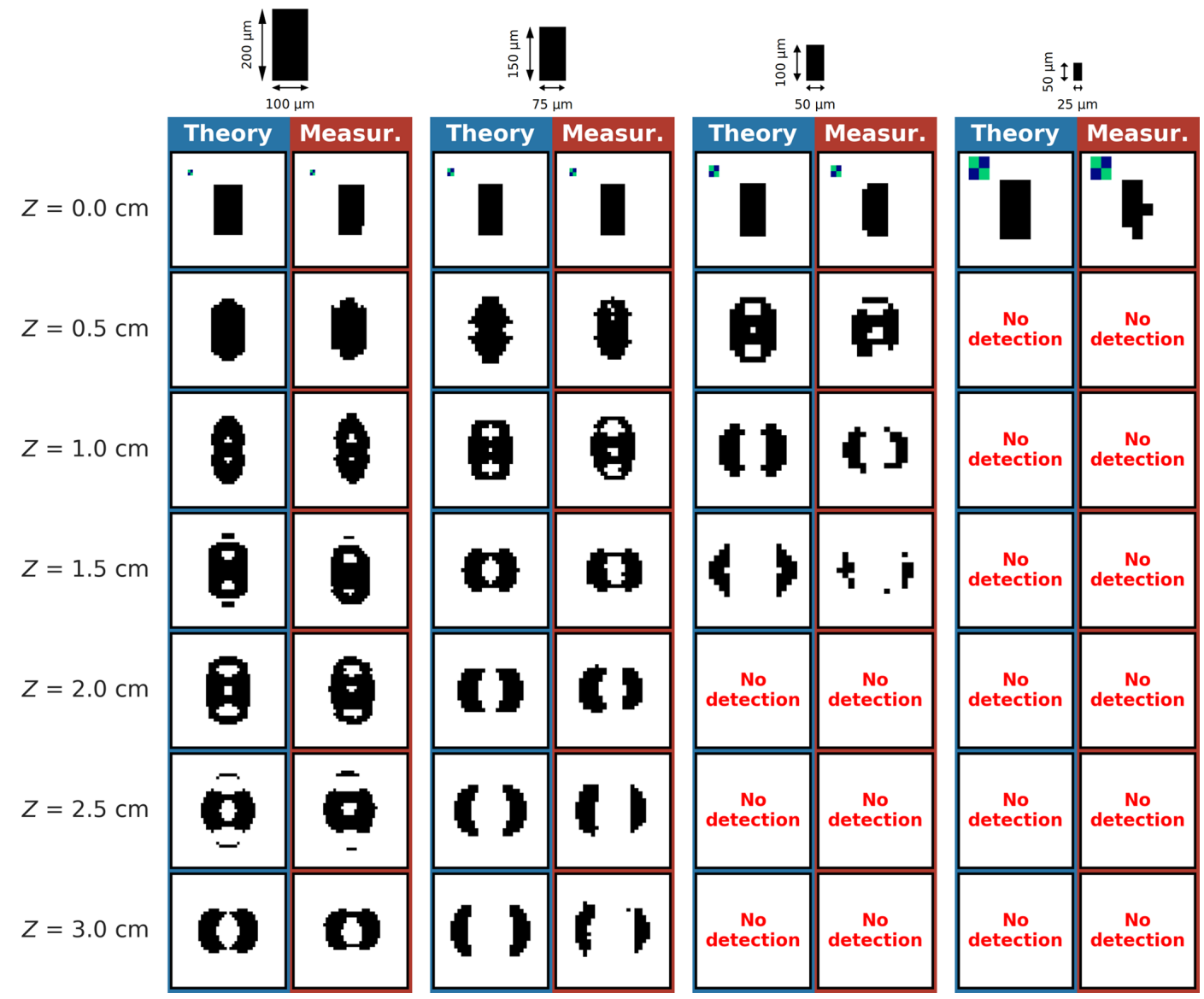

Figure 5. Theoretical and measured $2 \mathrm{D}-\mathrm{S}$ diffracting patterns of $1: 2$ (width: height) opaque rectangular planar shape particles (short columns) at several distances $Z$ from the object plane. Images are framed according to the particle size; the blue and green target in the first line shows the $2 \times 2$-pixel scale for the images in the entire column below.

pixelization. Note that images are framed according to the particle size; i.e., smaller particle images are up-scaled with respect to larger ones. Each line shows results for particles at a specific distance $Z$ from the object plane $(Z=0 \mathrm{~cm})$ to a distance very close to the arm of the probe $(Z=3 \mathrm{~cm})$. Results obtained for negative values of $Z$ look very similar (not shown). Note that different particle orientations $\left(0,90^{\circ}\right.$; see Sect. 2.2) were chosen for the measurements in order to avoid splitting of a particle into two or more images by the probe's image separator, at least in one orientation. A striking result is that measurements obtained with the 2D-S probe are in really good agreement with the theoretical diffraction simulation results, not only in terms of diffraction pattern, but also with respect to the DoF limit which is illustrated by the disappearing image at approximately the same $Z$ value in theory and the corresponding measurement. We notice that several Poisson spots can appear in the same particle shadow, as observed for example for the $100 \times 200 \mu \mathrm{m}$ particle passing at $Z=2 \mathrm{~cm}$ in both the simulation and the measurement. In contrast to opaque disc particles which preserve their contour shape, columns recorded by the $2 \mathrm{D}-\mathrm{S}$ can end up in 2-D images that are very different from a column, as seen for the $75 \times 150 \mu \mathrm{m}$ particle at $Z=1.5 \mathrm{~cm}$. The image resembles more a disc with Poisson's spot than a column. Also, particle images can present small patterns detached from the main particle, as seen at $Z=1.5$ and $Z=2.5 \mathrm{~cm}$ for the $100 \times 200 \mu \mathrm{m}$ particle. Approaching the DoF limit, the columnar particle is split into two symmetrical particles with the shape of a "crescent moon". The evolution of the particle shape with $Z$ with a $0.01 \mu \mathrm{m}$ step is shown in the Supplement videos (available here: columnar particle with sizes of $25 \times 50 \mu \mathrm{m}$ (https://doi.org/10.5446/40656), $50 \times 100 \mu \mathrm{m}$ (https://doi.org/10.5446/40658), $75 \times 150 \mu \mathrm{m}$ (https://doi.org/10.5446/40660), and $100 \times 200 \mu \mathrm{m}$ (https://doi.org/10.5446/40662)).

Figure 6 then shows results for a $1: 4$ (width : height) elongated column with three different sizes.

Comparison between theory and measurements again shows very good agreement. Also for this crystal geometry, diffraction can produce patterns that are very different compared to the initial shape. In addition, we notice that these patterns look very different than those found 


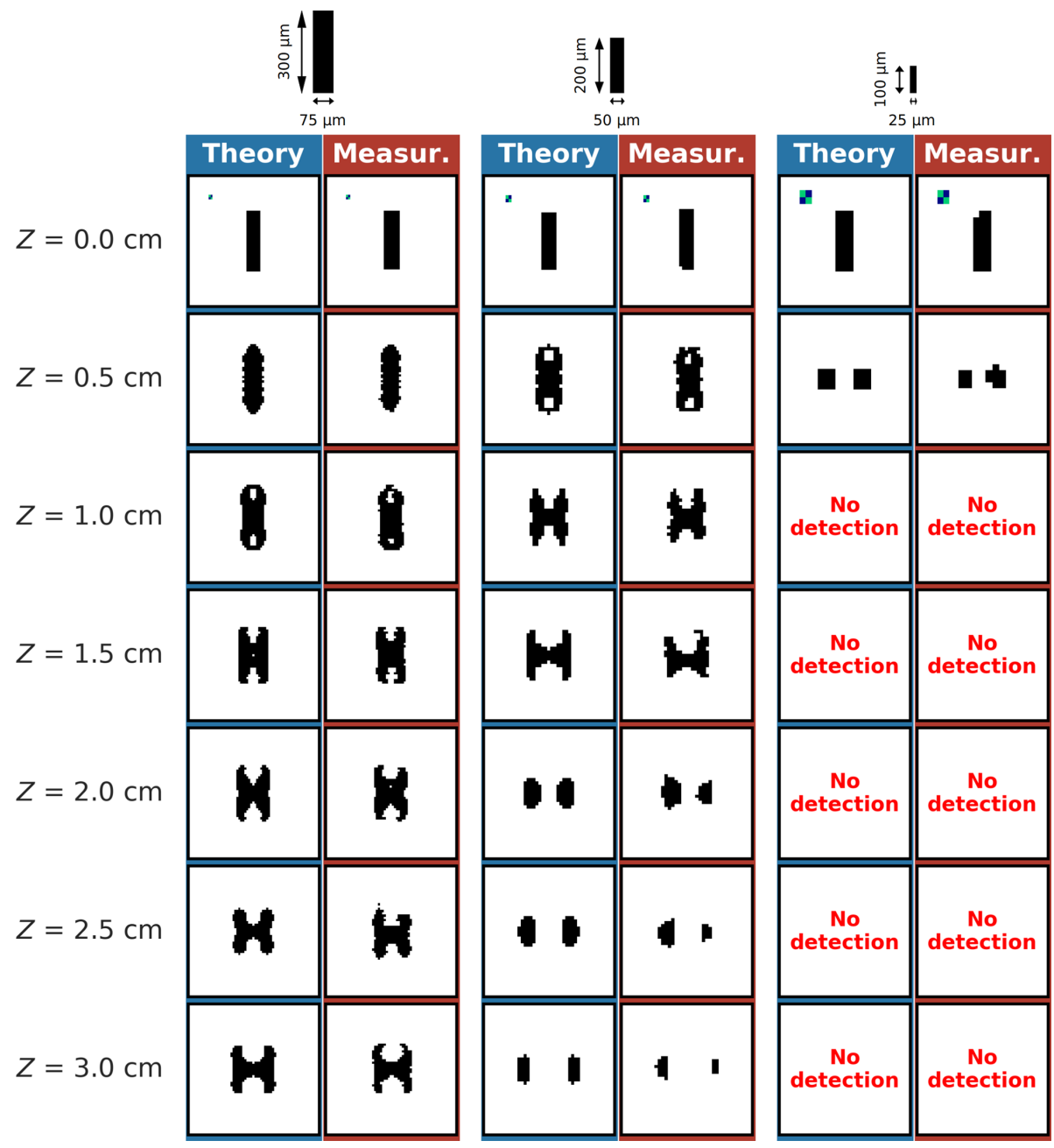

Figure 6. As Fig. 5 for $1: 4$ (width : height) opaque rectangular planar shape particles (elongated columns).

in Fig. 5 for the shorter columns. Here, the diffraction pattern turns into a capped columnar shape as $Z$ increases (see, e.g., $75 \times 300 \mu \mathrm{m}$ particle at $Z=3 \mathrm{~cm}$ ) and ends by splitting into two symmetrical particles when $Z$ approaches the DoF limit (see, e.g., $50 \times 200 \mu \mathrm{m}$ particle with $Z>2 \mathrm{~cm}$ ). This is also illustrated in the Supplement videos (available here: columnar particle with sizes of $25 \times 100 \mu \mathrm{m}$ (https://doi.org/10.5446/40657), $50 \times$ $200 \mu \mathrm{m}$ (https://doi.org/10.5446/40659), and $75 \times 300 \mu \mathrm{m}$ (https://doi.org/10.5446/40661)).

Figure 7 shows results for four capped columnar particles with different ratios and sizes.

Once again, the very good agreement between simulated and recorded images is striking. The diffraction pattern for one individual capped columnar particle can adopt many different image shapes, as can be seen for example for the $150 \times 250 \mu \mathrm{m}$ capped column. We notice that several small patterns may be detached from the main particle as a function of distance $Z$ from the object plane. We also notice that capped columnar particles can fall apart into three distinct "large" parts in the produced binary diffraction image as seen for the $200 \times 150 \mu \mathrm{m}$ particle at $Z=$ $2 \mathrm{~cm}$. The Supplement videos (available here: capped columnar particle with sizes of $75 \times 125 \mu \mathrm{m}$ with $25 \times 25 \mu \mathrm{m}$ bar (https://doi.org/10.5446/40652), $100 \times 75 \mu \mathrm{m}$ with $50 \times 25 \mu \mathrm{m}$ bar (https://doi.org/10.5446/40653), $150 \times 250 \mu \mathrm{m}$ with $50 \times$ $50 \mu \mathrm{m}$ bar (https://doi.org/10.5446/40654), and $200 \times 150 \mu \mathrm{m}$ with $100 \times 50 \mu \mathrm{m}$ bar (https://doi.org/10.5446/40655)) are very helpful for visualizing the evolution of the diffraction pattern.

As a particle moves away from the object plane, we notice that its image becomes more and more roundish regardless of its initial shape. The information of the real shape of the particle ends up being lost as the diffraction patterns progressively adopt a more circular form. This is particularly striking on videos. This means that any particle shape far from the object plane produces a more and more circular diffraction pattern which no longer allows us to identify the original shape of the respective particle. See for example the theoretical $75 \times 125 \mu \mathrm{m}$ capped columnar particle diffraction 


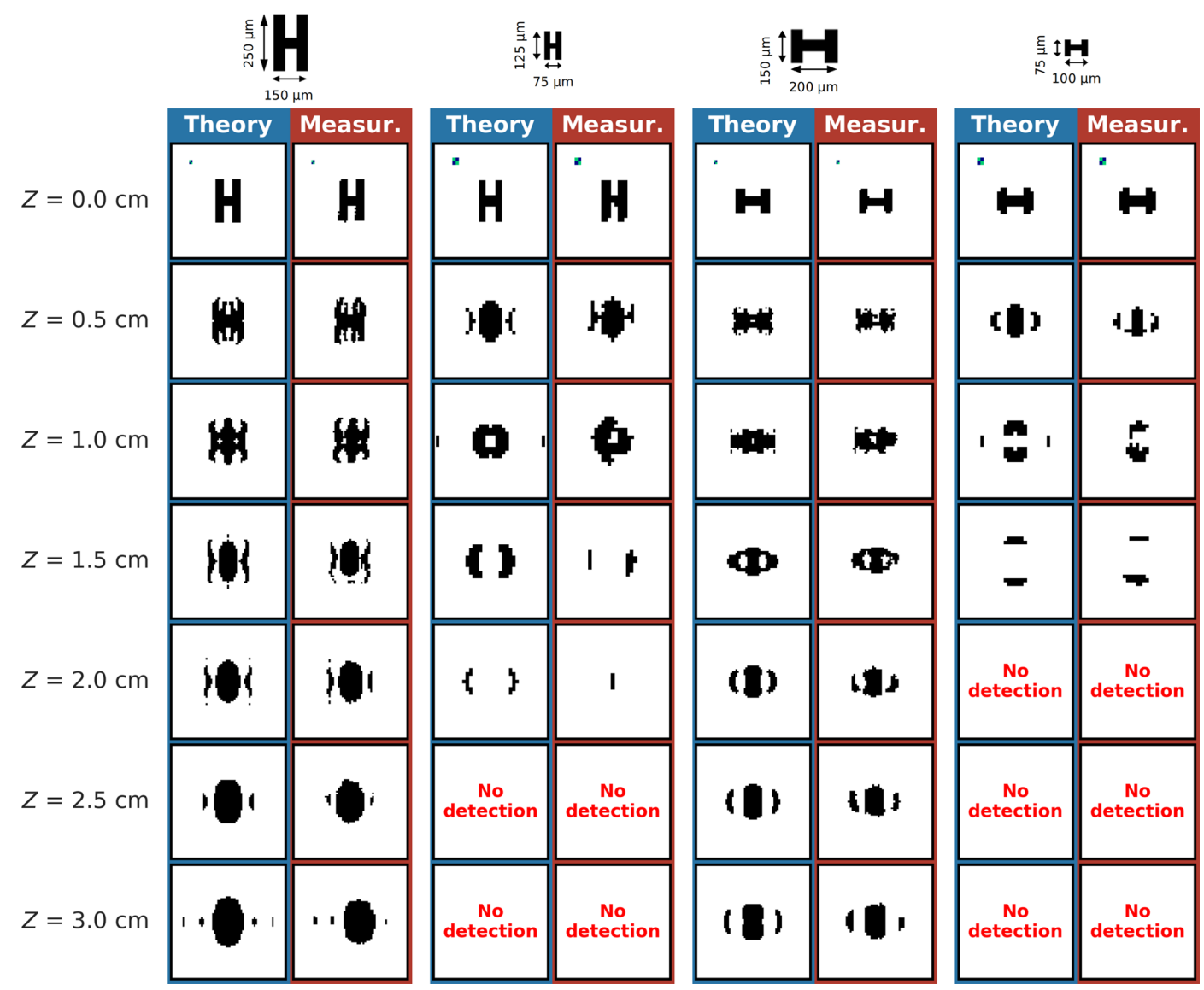

Figure 7. As Fig. 5 for opaque capped columnar planar shape particles: $250 \times 150 \mu \mathrm{m}$ (external edges) with $50 \times 50 \mu \mathrm{m}$ mid-column, $125 \times$ $75 \mu \mathrm{m}$ with $25 \times 25 \mu \mathrm{m}$ mid-column, $150 \times 200 \mu \mathrm{m}$ with $50 \times 100 \mu \mathrm{m}$ mid-column, and $75 \times 100 \mu \mathrm{m}$ with $25 \times 50 \mu \mathrm{m}$ mid-column.

pattern at $Z=1 \mathrm{~cm}$ (Fig. 7) or the theoretical and measured $75 \times 150 \mu \mathrm{m}$ short column diffraction pattern at $Z=1.5 \mathrm{~cm}$ (Fig. 5). Depending on the initial shape, the binary diffraction pattern is generally broken into two, sometimes three image parts of similar sizes when approaching the DoF limit. Depending on the orientation of the particle, these two or three particles can be interpreted as different particles by the $2 \mathrm{D}-\mathrm{S}$ probe. Indeed, the $2 \mathrm{D}-\mathrm{S}$ probe stores a new particle as soon as a slice with 128 white pixels (image separator set by probe) is found. Because these two or three "particles" are registered as very close particles in time, algorithms will generally remove these particles from the data set, thereby considering them to be particles generated from shattering (Field et al., 2006). This can create significant differences when particles are not properly recorded or deleted by the shattering algorithm before reaching the theoretical DoF limit. For example, the $75 \times 150 \mu \mathrm{m}$ short columnar particle (Fig. 5; second column) might be removed by the shattering algorithm beyond $Z=1.59 \mathrm{~cm}$ (see video in the Supplement available here: https://doi.org/10.5446/40660), whereas its theoretical DoF exceeds the distance between the arms. Therefore, it seriously affects the sample volume which is based on the DoF limit (Korolev et al., 1991) and consequently affects the retrieved concentrations.

Another interesting remark based on these results is that an out-of-focus image of a distinct particle shape can closely resemble another particle of a very different shape. As an example, note that the diffraction pattern of a $75 \times 300 \mu \mathrm{m}$ columnar particle at $Z=2.5 \mathrm{~cm}$ (Fig. 6) looks a lot like an infocus capped columnar particle in the object plane. Also, the diffraction pattern of a $75 \times 125 \mu \mathrm{m}$ capped columnar particle at $Z=1 \mathrm{~cm}$ (Fig. 7) looks like a disc with Poisson's spot, meaning that an out-of-focus capped columnar ice particle can be interpreted as a droplet faintly out-of-focus.

\subsection{Theoretical evolution of the equivalent and maximum particle diameters}

In this section, we present some diffraction simulation results for four chosen particle shapes to illustrate the evolution of the particle diameter, including uncertainty evaluation. Our purpose here is neither to present an exhaustive list of results related to each shape nor to quantify the uncertainty of the probe in an absolute manner. 
The size of the particle from a 2-D image has no absolute definition. Several definitions are used in the literature with different pros and cons depending on the objective of the study. In the study presented here, we illustrate results with two commonly used particle size definitions: the surfaceequivalent diameter $D_{\mathrm{eq}}$ and the maximum diameter $D_{\max }$. $D_{\text {eq }}$ is defined as the diameter of a disc with the same surface as the analyzed particle image. $D_{\max }$ is defined as the diameter of the smallest circle encompassing the particle image (e.g., Chrystal, 1885; Welzl, 1991; Heymsfield et al., 2013; $\mathrm{Wu}$ and McFarquhar, 2016). Note that all triggered pixels of the image are considered here for the computation of $D_{\text {eq }}$ and $D_{\max }$, even when the pattern is split into several fragments (see Sect. 3.1).

Figure 8 shows the theoretical evolution of $D_{\text {eq }}$ (solid blue line) and $D_{\max }$ (solid green line), applying the $50 \%$ threshold to a simulated $1 \times 1 \mu \mathrm{m}$ pixel image pattern, as a function of $Z$ for four different particles: two rectangles with very similar true $D_{\text {eq }}(119.7$ and $112.8 \mu \mathrm{m})$ but different aspect ratios (1: 2 and $1: 4$, or short and elongate columns, respectively) and two capped column-type particles with the same shape but different sizes.

Dashed lines show the true $D_{\text {eq }}$ and $D_{\text {max }}$ particle diameters. The produced binary images from diffraction simulations are presented on top of each sub-figure of Fig. 8 for a few distinct distances of $Z(Z=0,0.5,1.0, \ldots$, and $3.0 \mathrm{~cm}$ ). Blue and green shadow areas in this figure show $D_{\text {eq }}$ and $D_{\max }$ for the theoretical records by the 2D-S (pixel of $10 \times 11.4 \mu \mathrm{m}$ ). Indeed, a spread for each size would appear due to the discrete pixel effect. As a photodiode needs to be shadowed from at least $50 \%$ light intensity to be triggered, the number of triggered pixels will depend on the position of the particle shadow on the photodiode array of the probe. To account for this discrete pixel effect, particles are systematically shifted over one $10 \times 11.4 \mu \mathrm{m} 2 \mathrm{D}-\mathrm{S}$ pixel by increments of $1 \mu \mathrm{m}$ in both directions. This discrete pixel effect is illustrated in the Supplement video (available here: https://doi.org/10.5446/40663), showing the $150 \times 250 \mu \mathrm{m}$ capped columnar particle at $Z=0.5 \mathrm{~cm}$. We note that the pixels at the edge can be triggered or not as the particle is shifted, which then affects the particle size.

At first, we discuss diffraction simulation results of short and elongated columns presented in Figs. 8a and 8b. Both figures illustrate the evolution of $D_{\mathrm{eq}}$ and $D_{\mathrm{max}}$ as both particles pass the laser beam between $Z=0$ and $Z=3.1 \mathrm{~cm}$. The evolution of $D_{\mathrm{eq}}$ is rather smooth with varying $Z$, compared to $D_{\max }$ evolution, which is much more oscillating. Still, both columnar particles have a comparable true $D_{\text {eq }}(119.7 \mu \mathrm{m}$ versus $112.8 \mu \mathrm{m}$ ), and both $D_{\max }$ and $D_{\text {eq }}$ evolution show some nice similarities. Nevertheless, between $Z=0$ and $Z=$ $3.1 \mathrm{~cm}$, for the short column (Fig. 8a) $D_{\text {eq }}$ and $D_{\max }$ from theoretical binary images are always greater than the corresponding true $D_{\text {eq }}(119.7 \mu \mathrm{m})$ and $D_{\max }(168.6 \mu \mathrm{m})$ values, whereas the $D_{\text {eq }}$ and $D_{\max }$ retrieved from binary diffraction images of the elongated column (Fig. 8b) are lying on
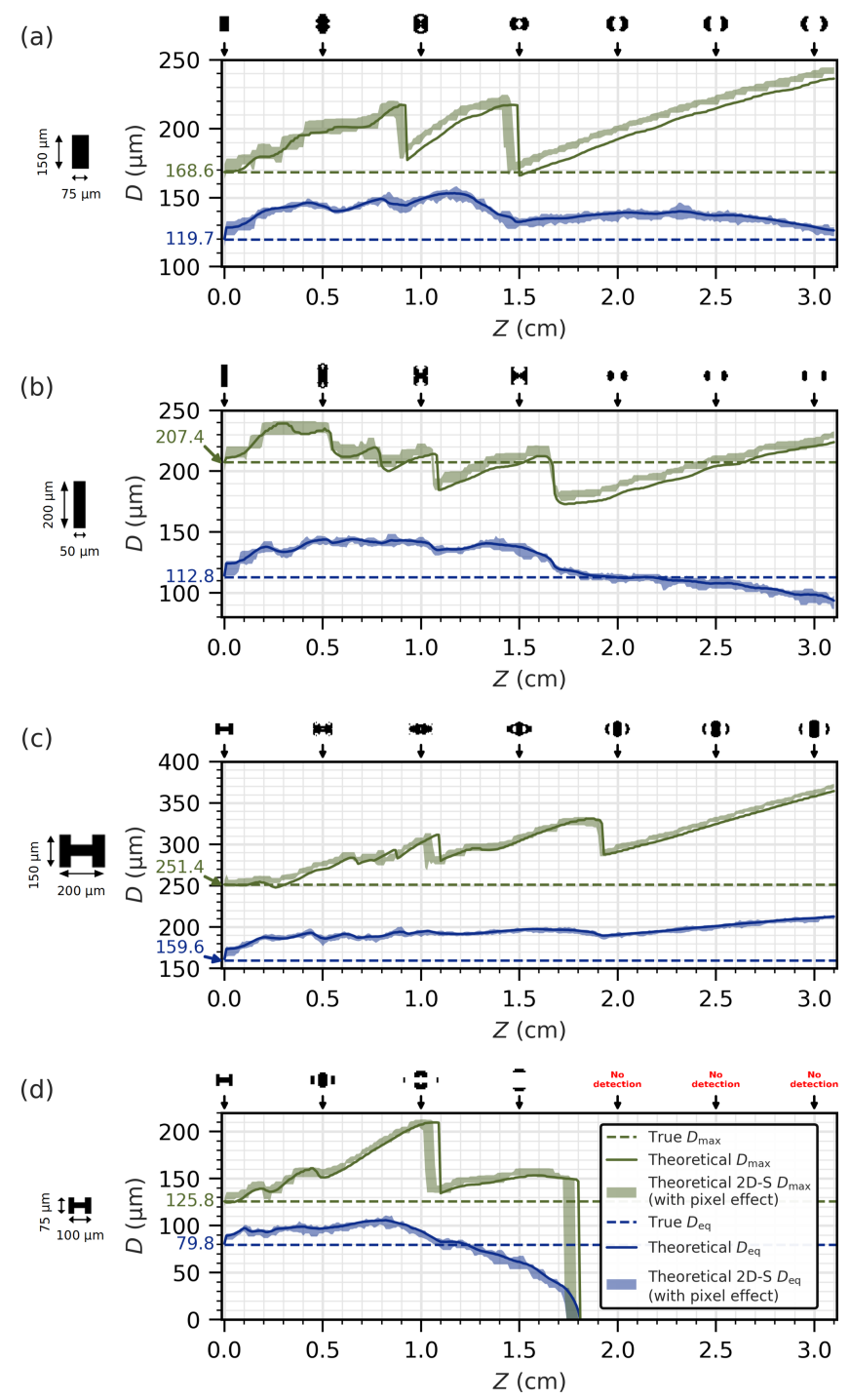

Figure 8. Evolution of the theoretical $D_{\text {eq }}$ (solid blue line) and $D_{\text {max }}$ (solid green line) of the diffracting image of a particle as a function of $Z$ (with a $50 \%$ intensity threshold), compared to the true $D_{\text {eq }}$ (dashed blue line) and the true $D_{\max }$ (dashed green line) of the particle. Binary images from diffraction patterns added on top of four figures for several $Z$ distances. Blue and green shadow areas are the theoretical records by the $2 \mathrm{D}-\mathrm{S}$ with the uncertainty due to the position of the particle in front of the photodiode array. Only $0^{\circ}$ particle orientation is considered here.

either side of the theoretical value lines, $D_{\text {eq }}=112.8$ and $D_{\max }=207.4 \mu \mathrm{m}$. Repeated abrupt decreases in measured $D_{\max }$ are related to changes in the outer binary pixel ensembles of the diffraction pattern which are drifting away from the particle center as $Z$ increases. This then leads to sudden loss of outer pixel and related decrease in $D_{\max }$. Detaching pixel ensembles are frequently observed, with two to three produced sub-images stemming from the diffraction pattern of one particle. This can lead to virtually large $D_{\max }$ 
(e.g., $D_{\max }=240 \mu \mathrm{m}$ for the short column at $Z=3.0 \mathrm{~cm}$ corresponding to the true $D_{\max }$ of $168.6 \mu \mathrm{m}$ ).

Secondly, the two capped column-type particles are discussed. With increasing $Z$, the size of the larger capped column (Fig. 8c) increases for both diameter definitions $D_{\text {eq }}$ and $D_{\max } . D_{\text {eq }}$ of this particle when observed at a distance of $3 \mathrm{~cm}$ is about $210 \mu \mathrm{m}$, which exceeds by $50 \mu \mathrm{m}$ the true $D_{\text {eq }}$ of $159.6 \mu \mathrm{m}$ of the particle. Also, $D_{\max }$ generally increases with increasing $Z$, however with few transient smaller diameter decreases at some distances depending on the evolution of the diffraction pattern details at the edges of the binary particle image. The smaller capped columnar particle (Fig. 8d) disappears before reaching $Z=3.1 \mathrm{~cm}$ (arm limit). The apparent particle size first grows with $Z$, then shrinks continuously in terms of $D_{\text {eq }}$ (more abruptly in terms of $D_{\max }$ ), followed by another phase of slight increase in $D_{\max }$, before the particle then completely disappears in both diameter definitions at a distance $Z$ of roughly $1.8 \mathrm{~cm}$. Again, it can be noticed that in general $D_{\text {eq }}$ changes more gently with $Z$, as compared to $D_{\max }$. Close to the DoF limit, which is estimated from diffraction simulations for the particle in Fig. $8 \mathrm{~d}$ as the position $Z$ where the binary image disappears (roughly at $Z=1.8 \mathrm{~cm}), D_{\text {eq }}$ is underestimated, whereas $D_{\max }$ continues to be overestimated as the particle image is formed by a few distant pixels. We note also that DoF limits from calculations of $Z_{\max }=D^{2} Z_{\mathrm{d} \max } /(4 \lambda)$ produces different DoF limit values for $D_{\text {eq }}$ and $D_{\max }$ size definitions for the same particle (DMT, 2009; SPEC, 2011). The DoF limit values are $Z_{\max }=1.66$ (using $D_{\text {eq }}$ ) and $Z_{\max }=4.13 \mathrm{~cm}$ (using $D_{\max }$ ). These different DoF limit estimations (factor of 2.5 between both calculations) using the above equation for this particle means different sample volumes, and finally different concentrations. For this particle, using the DoF limit estimations with $D_{\text {eq }}$ would be closer to the DoF limit $(Z=1.8 \mathrm{~cm})$ found from diffraction simulation. Moreover, as the uncertainty in $D_{\text {eq }}$ for out-of-focus particles is relatively small (Table 2) compared to $D_{\max }$ (Fig. 8), it should be a relatively good option to estimate the DoF limit. However, our arbitrary diameter definition used in the classical DoF limit calculation remains questionable, since ice particles are primarily non-spherical.

Furthermore, for both columnar and capped columnar particles, it is evident that the discrete pixel effect (shadow areas) is almost negligible with respect to the diameter variability along the $Z$ distance according to the diffraction simulations.

Finally, Table 1 summarizes Fig. 8 in terms of maximum, minimum, and average $D_{\text {eq }}$ and $D_{\max }$ diameters over the whole distance between the two arms of the 2D-S probe compared to the true $D_{\text {eq }}$ and $D_{\max }$. For these four particles, we note that uncertainty for particles with a DoF limit beyond the arm limit spans from $-23 \%$ to $+35 \%$ in $D_{\text {eq }}$ and from $-15 \%$ to $+48 \%$ in $D_{\max }$. For the smallest particle, uncertainty spans from $-85 \%$ to $+39 \%$ in $D_{\text {eq }}$ and from $-88 \%$ to $+69 \%$ in $D_{\max }$. For this small particle, with a DoF limit smaller than the arm limit, the lower bound of the uncertainty has been calculated for a 1-pixel particle.

\subsection{Comparison of theoretical statistics with measurements}

In this section, we compare particle size distributions retrieved theoretically from diffraction pattern simulations and experimentally measured by the $2 \mathrm{D}-\mathrm{S}$ probe. For the measurements, a spinning disc (Fig. 3b) has been utilized with imprinted short columnar particles shown in Fig. 5. The spinning disc contains four different particle sizes, all of them imprinted in three different orientations $\left(0,45\right.$, and $\left.90^{\circ}\right)$ and repeated six times. Therefore, each particle size should be seen 18 times at each revolution of the spinning disc. We simulate and measure $10 \mathrm{~s}$ of disc spinning at $108.6 \pm 0.2 \mathrm{rps}$ $\left(\approx 9.5 \mathrm{~m} \mathrm{~s}^{-1}\right.$ in equivalent particle speed), which should result for each of the four short columns in about $19500 \mathrm{im}-$ ages; $9.5 \mathrm{~m} \mathrm{~s}^{-1}$ already represents the maximum equivalent speed of particles on the rotating disc, which is small compared to aircraft speeds and therefore does not allow us to study possible effects of electronic response time related to disc speed.

Figure 9a shows theoretical results obtained from diffraction patterns by simulating each of the four particles 19500 times.

Each of the three orientations $\left(0,45\right.$, and $\left.90^{\circ}\right)$ accounts for one-third of the contribution of each of the four particles to the particle size distribution. The true equivalent diameter $D_{\text {eq }}$ of a $100 \times 200 \mu \mathrm{m}$ particle is $159.6 \mu \mathrm{m}$. At $Z=0 \mathrm{~cm}$, the particle image projected onto the photodiode array is undistorted. However, we see in Fig. 9a that the diameter is not retrieved perfectly and is also slightly varying. Depending on the position of the shadow particle projected onto the photodiode array, $D_{\text {eq }}$ can vary from 152 to $169 \mu \mathrm{m}$, which is due to taking into account the discrete pixel effect. Therefore, even in the best case when particles cross the laser beam of the 2D-S in the object plane and without any noise, this particle can be recorded with an uncertainty in $D_{\text {eq }}$ of up to $6 \%$, only due to the discrete pixel effect. By moving the $100 \times 200 \mu \mathrm{m}$ particle away from the object plane to $Z=1 \mathrm{~cm}$, then $2 \mathrm{~cm}$, and finally $3 \mathrm{~cm}$, we notice that $D_{\text {eq }}$ first starts to increase, and then decreases. The described behavior depends on particle size and shape, but has a common feature: particle $D_{\text {eq }}$ generally starts to increase and then decreases until it disappears when reaching the DoF limit, as shown for the small capped column in Fig. 8d.

Figure $9 \mathrm{~b}$ shows the size distribution of the four short columnar particles measured by the $2 \mathrm{D}-\mathrm{S}$. At $Z=0 \mathrm{~cm}$, the number of counted particles (yellow curve with four distinct modes attributed to four particle sizes) for the four particle sizes (from larger to smaller ones) is 19488,19484 , 19464 , and 29490 . Note that most of the very small particles $(<4$ pixels at $Z=0 \mathrm{~cm}$ ) are due to dust on the spinning disc (the first four bars of the orange histogram). The num- 
Table 1. True $D_{\text {eq }}$ and $D_{\max }$ of particles shown in Fig. 8 compared with the minimum, maximum, and average theoretical $D_{\text {eq }}$ and $D_{\text {max }}$ over the whole distance between the two arms of the 2D-S probe. The minimum and maximum relative errors with respect to true $D_{\text {eq }}$ and $D_{\max }$ are shown in brackets behind minimum and maximum diameter values.

\begin{tabular}{lllll}
\hline & Column $75 \times 150 \mu \mathrm{m}$ & Column $50 \times 200 \mu \mathrm{m}$ & Capped column $200 \times 150 \mu \mathrm{m}$ & Capped column $100 \times 75 \mu \mathrm{m}$ \\
\hline True $D_{\text {eq }}$ & $119.7 \mu \mathrm{m}$ & $112.8 \mu \mathrm{m}$ & $159.6 \mu \mathrm{m}$ & $79.8 \mu \mathrm{m}$ \\
Mean $D_{\text {eq }}$ & $139.4 \mu \mathrm{m}$ & $124.2 \mu \mathrm{m}$ & $194.8 \mu \mathrm{m}$ & $48.3 \mu \mathrm{m}$ \\
Min $D_{\text {eq }}$ & $114.9 \mu \mathrm{m}(-4 \%)$ & $86.9 \mu \mathrm{m}(-23 \%)$ & $157.1 \mu \mathrm{m}(-2 \%)$ & $12.0 \mu \mathrm{m}(=1$ pixel $)(-85 \%)$ \\
Max $D_{\text {eq }}$ & $158.5 \mu \mathrm{m}(+32 \%)$ & $148.5 \mu \mathrm{m}(+32 \%)$ & $214.8 \mu \mathrm{m}(+35 \%)$ & $111.1 \mu \mathrm{m}(+39 \%)$ \\
\hline True $D_{\max }$ & $168.6 \mu \mathrm{m}$ & $207.4 \mu \mathrm{m}$ & $251.4 \mu \mathrm{m}$ & $125.8 \mu \mathrm{m}$ \\
Mean $D_{\max }$ & $200.8 \mu \mathrm{m}$ & $205.8 \mu \mathrm{m}$ & $301.9 \mu \mathrm{m}$ & $91.8 \mu \mathrm{m}$ \\
Min $D_{\max }$ & $163.9 \mu \mathrm{m}(-3 \%)$ & $175.6 \mu \mathrm{m}(-15 \%)$ & $248.9 \mu \mathrm{m}(-1 \%)$ & $15.2 \mu \mathrm{m}(=1 \mathrm{pixel})(-88 \%)$ \\
Max $D_{\max }$ & $244.6 \mu \mathrm{m}(+45 \%)$ & $241.5 \mu \mathrm{m}(+16 \%)$ & $373.0 \mu \mathrm{m}(+48 \%)$ & $213.1 \mu \mathrm{m}(+69 \%)$ \\
\hline
\end{tabular}

Table 2. Theoretical (measured) relative uncertainty $\Delta D_{\mathrm{eq}}=\varepsilon \pm \sigma$ for the four opaque short columnar shape particles shown in Fig. 9 with three orientations $\left(0,45\right.$, and $\left.90^{\circ}\right)$ of equal probability. $\varepsilon$ represents the relative mean error and $\sigma$ its relative standard deviation (due to the pixel effect) from the true $D_{\text {eq }}$. For the $25 \times 50 \mu \mathrm{m}$ short columnar particle at $Z=0$, only images with more than 4 pixels are considered.

\begin{tabular}{lllll}
\hline & $\begin{array}{l}100 \times 200 \mu \mathrm{m} \\
{\left[\text { True } D_{\mathrm{eq}}=159.6 \mu \mathrm{m}\right]}\end{array}$ & $\begin{array}{l}75 \times 150 \mu \mathrm{m} \\
{\left[\text { True } D_{\mathrm{eq}}=119.7 \mu \mathrm{m}\right]}\end{array}$ & $\begin{array}{l}50 \times 100 \mu \mathrm{m} \\
{\left[\text { True } D_{\mathrm{eq}}=79.8 \mu \mathrm{m}\right]}\end{array}$ & $\begin{array}{l}25 \times 50 \mu \mathrm{m} \\
{\left[\text { True } D_{\text {eq }}=39.9 \mu \mathrm{m}\right]}\end{array}$ \\
\hline$Z=0 \mathrm{~cm}$ & $0 \% \pm 1 \%(1 \% \pm 1 \%)$ & $0 \% \pm 2 \%(2 \% \pm 2 \%)$ & $0 \% \pm 3 \%(3 \% \pm 3 \%)$ & $0 \% \pm 7 \%(14 \% \pm 7 \%)$ \\
$Z=1 \mathrm{~cm}$ & $17 \% \pm 0 \%(13 \% \pm 2 \%)$ & $24 \% \pm 1 \%(18 \% \pm 3 \%)$ & $16 \% \pm 1 \%(11 \% \pm 13 \%)$ & No detection (No detection) \\
$Z=2 \mathrm{~cm}$ & $27 \% \pm 1 \%(22 \% \pm 3 \%)$ & $15 \% \pm 1 \%(6 \% \pm 10 \%)$ & No detection (No detection) & No detection (No detection) \\
$Z=3 \mathrm{~cm}$ & $13 \% \pm 0 \%(8 \% \pm 4 \%)$ & $6 \% \pm 1 \%(28 \% \pm 13 \%)$ & No detection (No detection) & No detection (No detection) \\
\hline
\end{tabular}

ber of counted particles smaller than 4 pixels at $Z=0 \mathrm{~cm}$ is 12029. At $Z=0 \mathrm{~cm}$, the four observed particle modes can be clearly attributed to the four different short columnar particle sizes. Distributions show reasonably narrow peaks. The position of the individual peaks is on average $5 \mu \mathrm{m}$ below the expected respective true $D_{\text {eq }}$, which is half of the pixel size. Experimentally, the discrete photodiodes in the array and the $50 \%$ occultation criterion introduce a digitization uncertainty of roughly 1 size resolution ( $=10 \mu \mathrm{m}$ for the $2 \mathrm{D}-\mathrm{S})$ depending upon where the particle passes across the array (Baumgardner et al., 2017). We recall also that we found a mean value of $11.4 \mu \mathrm{m}$ for the pixel size along the photodiode array based on our own calibration using a spinning glass disc with a printed opaque disc shape of $800 \mu \mathrm{m}$ in diameter. Smaller size effects could be that different particles cross different photodiodes at different positions of the linear photodiode array, which is due to the fact that the rotation axis and the spinning glass disc center are not perfectly coaxial. Indeed, all photodiodes may not have an identical response. With increasing values of $Z>0 \mathrm{~cm}$, distributions of individual modes are getting broader. Whereas at $Z=1 \mathrm{~cm}$ the three larger particles are observed, at $Z=2$ and $Z=3 \mathrm{~cm}$ solely the two larger particles have their DoF beyond these distances. For the larger short columnar particle $(100 \times 200 \mu \mathrm{m})$, the four peaks corresponding to the four distances $Z$ are well located compared to theoretical results, and each peak contains $19500 \pm 20$ records. The second larger short columnar particle $(75 \times 150 \mu \mathrm{m})$ shows quite good agreement with simulations for peak position at $Z=1$ and $Z=2 \mathrm{~cm}$, and contains 19514 and 18548 records, respectively. The missing particles at $Z=2 \mathrm{~cm}$ appear in the very small mode centered around $90 \mu \mathrm{m}$. In this small mode, we found 1924 particles which correspond to 962 particles split into two parts (Fig. 5). Results at $Z=3 \mathrm{~cm}$ show two distinct modes centered on 72 and $102 \mu \mathrm{m}$, well below the theoretical peak at $128 \mu \mathrm{m}$. The $102 \mu \mathrm{m}$ mode is due to split particles with 45 and $90^{\circ}$ orientations which were not separated by the probe into two images. This mode is not centered as the theoretical mode $(128 \mu \mathrm{m})$ because the split particles show fewer triggered pixels in measurements compared to theoretical simulations (see Fig. 5). This finding may be due to the fact that the probe's $50 \%$ threshold does not perfectly coincide with the theoretical $50 \%$ threshold. This effect may particularly impact the resulting probe images when approaching the DoF limit. The $72 \mu \mathrm{m}$ mode is due to split particles with $0^{\circ}$ orientation such that a separator can be set by the probe which generates two smaller particles. The sum of the record number in the larger mode corresponding to 45 and $90^{\circ}$ orientations (13090) and half of the smaller mode corresponding to $0^{\circ}$ orientation (6403) yields in total 19483 . The $50 \times 100 \mu \mathrm{m}$ short column also shows two modes at $Z=1 \mathrm{~cm}$ for the same reason. Particles smaller than $40 \mu \mathrm{m}$ in $D_{\mathrm{eq}}$ at $Z \geq 1 \mathrm{~cm}$ are not dust particles on the spinning disc since their DoF limit is smaller than $Z=1 \mathrm{~cm}$. Actually, it can be seen from visual inspection of consecutive images that these small particles result from the separation of very small 


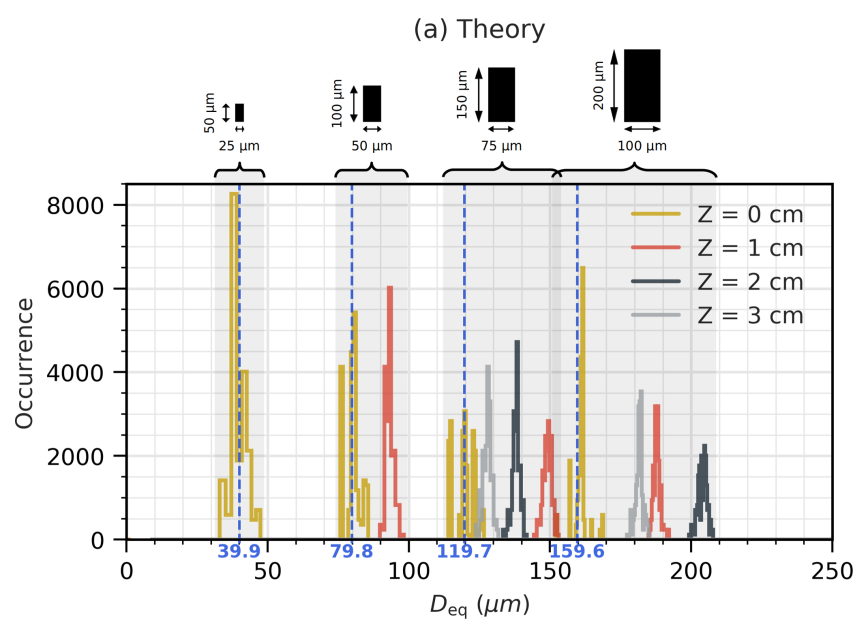

(b) Measurements

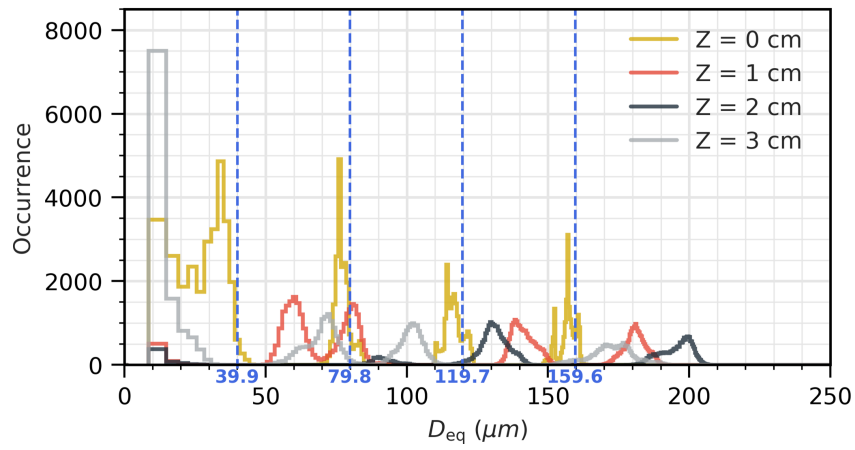

Figure 9. (a) Theoretical 2D-S $D_{\text {eq }}$ size distribution for opaque short columnar particles shown in Fig. 5. Each particle at each $Z$ is simulated 19500 times with three orientations $\left(0,45\right.$, and $\left.90^{\circ}\right)$ and with different positions over the photodiode array. Uncertainty is then due to diffraction and to the discrete pixel effect. (b) 2D-S size distribution for the same four short columnar particles imprinted with three orientations $\left(0,45\right.$, and $\left.90^{\circ}\right)$ on the spinning disc.

patterns from the main particles at the edge of the diffraction image. This effect is particularly striking at $Z=3 \mathrm{~cm}$ and is consistent with findings published in the literature. For example, fragmented diffraction patterns of spherical droplets traversing the sample area near the edges of the DoF were shown in the work by Korolev (2007); diffraction fringes around out-of-focus images measured by CIP were underscored by Korolev and Field (2015). "Reacceptance" algorithms (e.g., Korolev and Field, 2015; McFarquhar et al., 2017a) should address rigorously the problem of intact, i.e., not shattered, but fragmented particles.

We stated in Sect. 3.2 that the uncertainty in $D_{\text {eq }}$ due to diffraction in the out-of-focus region is far more important than the discrete pixel effect uncertainty. Table 2 shows the theoretical and measured uncertainty $\Delta D_{\mathrm{eq}}=\varepsilon \pm \sigma$ for the four opaque short columnar particles shown in Fig. 9, where $\varepsilon$ represents the relative mean error and $\sigma$ its relative standard deviation, both with respect to the true $D_{\text {eq }}$. We notice that standard deviation $\sigma$, both in theory and measurements, is generally small compared to the mean error $\varepsilon$ for out-offocus particles, except when measurements present a twomodal distribution as seen for the $75 \times 150 \mu \mathrm{m}$ short columnar particle at $Z=2$ and $Z=3 \mathrm{~cm}$, and for the $50 \times 100 \mu \mathrm{m}$ short columnar particle at $Z=1 \mathrm{~cm}$. For these specific cases, we notice that particles with true $D_{\text {eq }}$ larger than $100 \mu \mathrm{m}$ can have uncertainties up to $27 \% \pm 1 \%$ theoretically and up to $28 \% \pm 13 \%$ in measurements when split particles appear. Particles with true $D_{\text {eq }}$ smaller than $100 \mu$ m (the two smaller short columns of Fig. 5) do not show uncertainties larger than derived for the two larger particles in this table because uncertainties are solely quantified for a few discrete $Z$ distances. Uncertainties for particles smaller than $100 \mu \mathrm{m}$ would dramatically increase as $Z$ approaches the DoF limit as shown in Fig. 8d.

\section{Conclusions}

We presented in this study a first comparison of theoretical diffraction simulations of non-spherical cloud particles and respective image responses of OAP probes. First, the angular spectrum method has been applied to obtain diffraction patterns of spherical and non-spherical particles when viewed at specific distances from the object plane. For exemplary cloud particle shapes, diffraction simulations help in studying how the diameter retrieved from 2-D binary images is impacted by the distance from the object plane where the particle crosses the laser beam. Furthermore, we compared theoretical results with experimental measurements made with a $2 \mathrm{D}-\mathrm{S}$ probe. The main results are the following.

1. The diffraction image formed by an opaque planar particle, illuminated perpendicularly by a monochromatic coherent homogeneous plane wave, at a distance $Z$ beyond the object plane can be computed using angular spectrum theory.

2. Circular particles with diameters larger than $806 \mu \mathrm{m}$ are theoretically always recorded by the $2 \mathrm{D}-\mathrm{S}$ probe without noteworthy size deformation $(<10 \%)$.

3. Circular particles with diameters larger than $109 \mu \mathrm{m}$ are theoretically always recorded by the $2 \mathrm{D}-\mathrm{S}$ (potentially with huge deformation), whereas particles smaller than $109 \mu \mathrm{m}$ theoretically are no longer detectable once outof-DoF.

4. Theoretical diffraction simulations allow us to estimate DoF limits (as from Figs. 5-7 and 9d) which are consistent with the measurements.

5. Diffraction images of out-of-focus particles are sometimes very similar to other in-focus particle shapes. As an example, we observe that an out-of-focus elongated columnar ice particle can be interpreted as an in-focus capped columnar ice particle. An out-of-focus capped 
column can also be viewed as a droplet faintly out-offocus.

6. In general, diffraction images of all kinds of particle shapes consecutively lose their real shape information with increasing distance $Z$. Diffraction images show circular fringes, which is the reason why particle image edges tend to arch when $Z$ increases.

7. Due to the finite pixel size of the probe and the $50 \%$ occultation threshold, there is an uncertainty in the particle size measurements, even when $Z=0 \mathrm{~cm}$. For the four short columnar particles presented in this study, this digitization uncertainty is less than $7 \%$ in $D_{\text {eq. }}$. However, uncertainty for an out-of-focus particle is far more important and easily reaches several tens of percent of its diameter. These uncertainties are well retrieved experimentally. Also, experimental size distributions are broader than theoretical distributions due to optical and electronic noises. According to the Baumgardner et al. (2017) overview paper, OAP probes are considered to size correctly particles smaller than $100 \mu \mathrm{m}$ and larger than $100-200 \mu \mathrm{m}$ to $\pm 50 \%$ and $\pm 20 \%$, respectively. For the three largest short columnar particles with true $D_{\text {eq }}$ and true $D_{\max }$ of 112.8-159.6 and 168.6-251.4 $\mu \mathrm{m}$, respectively, we found for the $2 \mathrm{D}-\mathrm{S}$ simulations an uncertainty that spans from $-23 \%$ to $+35 \%$ in $D_{\text {eq }}$ and from $-15 \%$ to $+48 \%$ in $D_{\max }$. For the smallest particle, with a DoF limit smaller than the arm limit, with true $D_{\text {eq }}$ of $79.8 \mu \mathrm{m}$ and true $D_{\max }$ of $125.8 \mu \mathrm{m}$, we found an uncertainty that spans from $-85 \%$ to $+39 \%$ in $D_{\text {eq }}$ and from $-88 \%$ to $+69 \%$ in $D_{\max }$.

8. The intercomparison of theoretical and experimental $D_{\text {eq }}$ results for the four short columnar particles at distinct distances $Z$ shows a rather good agreement in retrieved uncertainties with respect to true $D_{\text {eq }}$, which is primarily driven by the diffraction effect and to a minor extent by the discrete pixel effect. This agreement deteriorates when particle patterns are separated into two or more images by the probe.

The good agreement between the simulated and measured diffraction patterns (see Figs. 5, 6, 7, and B1) suggests that the laser beam of the used 2D-S probe is well collimated and the use of the plane-wave approximation is well founded. Future investigations, especially concerning grayscale thresholds, could take into account properties of the laser beam and the optical system. For example, angular spectrum theory was used in the work by Hayman et al. (2016) to simulate the diffraction pattern of an opaque disc illuminated by an elliptical Gaussian beam, where an optical receiver point spread function was considered.

This study suggests that the incorrect particle sizing of cloud particles by OAPs is predominantly due to the diffraction effect in the out-of-focus region. Reducing the distance between the probe arms allows one to reduce diffraction effects, but simultaneously reduces the sampling volume. In order to reduce the sizing uncertainty, it would be extremely useful to get a direct and independent measure of the distance $Z$ at which a cloud particle crosses the laser beam of the probe. The knowledge of $Z$ would allow one to remove an unknown in inversion techniques to better estimate the true particle size of non-spherical particles in analogy to what has been suggested by Korolev (2007) for spherical particles. At the moment, we think that the simulation of diffraction images of various cloud particle shapes will help us to better characterize OAP uncertainties in terms of small particle concentrations. This topic has not been in the scope of this study. Small particle concentrations can be extremely wrong, which has its origins in artificial small particles from diffraction, shattering, photodiode malfunctioning, and other noise. Each artifact's small particle is assigned a very small DoF and thus sample volume (Bansemer and Heymsfield, 2018), leading to extremely overestimated small particle concentrations. Finally, assuming that real 3-D opaque particles produce diffraction images analogous to those obtained with their plane cross-section shape, the diffraction simulation method presented in this study will allow us to conceive an OAP simulator using numerical 3-D particles which can be randomly oriented. However, it should be noted that this method does not take into account reflection and refraction effects of the light which can be non-negligible for ice cloud particles.

Data availability. The data from this study can be obtained by contacting the corresponding author of this article. 


\section{Appendix A: Angular spectrum theory}

In this Appendix, we use the same terminology as has been used in Sect. 3.10 of the classic textbook by Goodman (1996). Suppose that a monochromatic plane wave is propagating in the positive $Z$ direction and the complex field across the $Z=0$ plane is represented by $U_{i}(x, y, 0)$. A diffracting structure is introduced in the plane $Z=0$. The amplitude transmittance function $t_{A}(x, y)$ is the ratio of the transmitted field amplitude $U_{t}(x, y, 0)$ to the incident field amplitude $U_{i}(x, y, 0)$ at each position $(x, y)$ in the $Z=0$ plane; that is,

$U_{t}(x, y, 0)=t_{A}(x, y) U_{i}(x, y, 0)$.

In this work, the amplitude transmittance function $t_{A}(x, y)$ is defined as follows:

$t_{A}(x, y)= \begin{cases}1 & \text { if outside the opaque shape } \\ 0 & \text { if in the opaque shape }\end{cases}$

and corresponds to the binary matrix representing the studied opaque shape.

In the Fourier domain, the angular spectrum of $U_{t}(x, y, 0)$ is

$A\left(f_{x}, f_{y}, 0\right)=\iint_{-\infty}^{+\infty} U_{t}(x, y, 0) e^{-i 2 \pi\left(f_{x} x+f_{y} y\right)} \mathrm{d} x \mathrm{~d} y$.

The angular spectrum of $U(x, y, z)$ at $Z=z$ is given by a solution of the differential equation which represents the Helmholtz equation in the Fourier domain (Ersoy, 2007). This solution can be written as

$A\left(f_{x}, f_{y}, z\right)=A\left(f_{x}, f_{y}, 0\right) H\left(f_{x}, f_{y}\right)$,

where $H\left(f_{x}, f_{y}\right)=e^{i z \sqrt{k^{2}-4 \pi^{2}\left(f_{x}^{2}+f_{y}^{2}\right)}}$ under the condition of homogeneous waves $\left(k^{2}>4 \pi^{2}\left(f_{x}^{2}+f_{y}^{2}\right)\right)$, which is the case in this study. Applying an inverse Fourier transform gives the resulting wave field at the distance $Z=z$ :

$U(x, y, z)=\int_{-\infty}^{+\infty} \int_{-\infty} A\left(f_{x}, f_{y}, z\right) e^{-i 2 \pi\left(f_{x} x+f_{y} y\right)} \mathrm{d} f_{x} \mathrm{~d} f_{y}$.

The diffraction pattern of the particle is then given by the intensity at $Z=z: I(x, y, z)=U(x, y, z)^{2}$.

Finally, a simple low-pass filter can be used to remove spurious noisy high frequencies. 
Appendix B: Comparison of theoretical diffraction patterns and measurements of disc shape particles on a spinning disc.

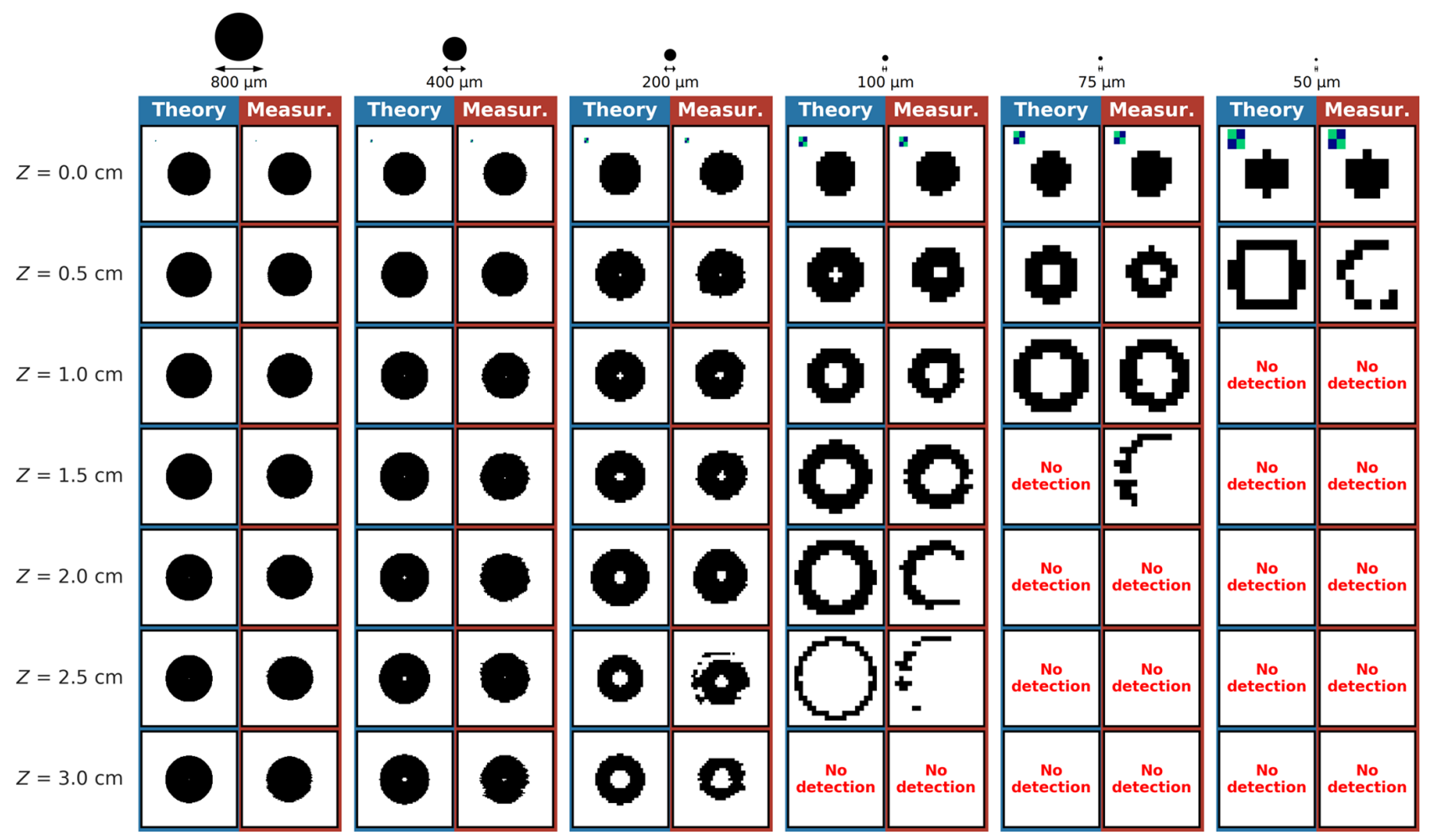

Figure B1. As Fig. 5 for opaque disc shape particles. Videos in the Supplement are available here: circular particle with radii of 25 (https://doi.org/10.5446/40646), 37.5 (https://doi.org/10.5446/ 40647), 50 (https://doi.org/10.5446/40648), 100 (https://doi.org/ 10.5446/40649), 200 (https://doi.org/10.5446/40650), and $400 \mu \mathrm{m}$ (https://doi.org/10.5446/40651). 
Supplement. Image sequences of diffraction patterns for particles at increasing distance from the object plane have been added as a Supplement. All videos are from the series "Simulations of cloud particle diffraction pattern" (Vaillant de Guélis, 2019) available on the TIB AV-Portal at https://av.tib.eu/series/627/simulations+of+ cloud+particle+diffraction+pattern. The supplement related to this article is available online at: https://doi.org/10.5194/amt-12-25132019-supplement.

Author contributions. TVdG wrote the manuscript. TVdG and VS performed the theoretical part. CG and BL conceived the test bench. TVdG made the experimental measurements. RD wrote the script to read the 2D-S raw data file. All the authors contributed discussion and feedback essential to the study.

Competing interests. The authors declare that they have no conflict of interest.

Acknowledgements. We would like to thank the FEMTO-ST Institute (UMR 6174) for conceiving the spinning glass discs. This work has been financially supported by the French government space agency CNES.

Review statement. This paper was edited by Wiebke Frey and reviewed by Darrel Baumgardner and one anonymous referee.

\section{References}

Bacon, N. J., Swanson, B. D., Baker, M. B., and Davis, E. J.: Breakup of levitated frost particles, J. Geophys. Res.-Atmos., 103, 13763-13775, https://doi.org/10.1029/98JD01162, 1998.

Baker, B., Mo, Q., Lawson, R. P., O'Connor, D., and Korolev, A.: Drop Size Distributions and the Lack of Small Drops in RICO Rain Shafts, J. Appl. Meteorol. Clim., 48, 616-623, https://doi.org/10.1175/2008JAMC1934.1, 2009.

Bansemer, A. and Heymsfield, A.: A Multi-Instrument Comparison of Small Ice Particle Size Distributions Measured from Aircraft, in: 15th Conference on Cloud Physics/15th Conference on Atmospheric Radiation, Vancouver, BC, Canada, 9-13 July, 2018.

Baumgardner, D., Abel, S. J., Axisa, D., Cotton, R., Crosier, J., Field, P., Gurganus, C., Heymsfield, A., Korolev, A., Krämer, M., Lawson, P., McFarquhar, G., Ulanowski, Z., and Um, J.: Cloud Ice Properties: In Situ Measurement Challenges, Meteor. Mon., 58, 9.1-9.23, https://doi.org/10.1175/AMSMONOGRAPHS-D16-0011.1, 2017.

Boucher, O., Randall, D., Artaxo, P., Bretherton, C., Feingold, G., Forster, P., Kerminen, V.-M., Kondo, Y., Liao, H., Lohmann, U., Rasch, P., Satheesh, S. K., Sherwood, S., Stevens, B., and Zhang, X. Y.: Clouds and aerosols, in: Climate change 2013: the physical science basis. Contribution of Working Group I to the Fifth Assessment Report of the Intergovernmental Panel on Climate Change, Cam- bridge University Press, UK and New York, USA, 571-657, https://doi.org/10.1017/CBO9781107415324.016, 2013.

Cantrell, W. and Heymsfield, A.: Production of Ice in Tropospheric Clouds: A Review, B. Am. Meteorol. Soc., 86, 795-808, https://doi.org/10.1175/BAMS-86-6-795, 2005.

Cho, H. R., Iribarne, J. V., and Richards, W. G.: On the orientation of ice crystals in a cumulonimbus cloud, J. Atmos. Sci., 38, 1111-1114, https://doi.org/10.1175/15200469(1981)038<1111:OTOOIC >2.0.CO;2, 1981.

Chrystal, M.: Sur le problème de la construction du cercle minimum renfermant $n$ points donnés d'un plan, B. Soc. Math. Fr., 13, 198200, https://doi.org/10.24033/bsmf.303, 1885.

Connolly, P. J., Flynn, M. J., Ulanowski, Z., Choularton, T. W., Gallagher, M. W., and Bower, K. N.: Calibration of the Cloud Particle Imager Probes Using Calibration Beads and Ice Crystal Analogs: The Depth of Field, J. Atmos. Ocean. Tech., 24, 18601879, https://doi.org/10.1175/JTECH2096.1, 2007.

DeMott, P. J., Hill, T. C. J., McCluskey, C. S., Prather, K. A., Collins, D. B., Sullivan, R. C., Ruppel, M. J., Mason, R. H., Irish, V. E., Lee, T., Hwang, C. Y., Rhee, T. S., Snider, J. R., McMeeking, G. R., Dhaniyala, S., Lewis, E. R., Wentzell, J. J. B., Abbatt, J., Lee, C., Sultana, C. M., Ault, A. P., Axson, J. L., Diaz Martinez, M., Venero, I., Santos-Figueroa, G., Stokes, M. D., Deane, G. B., Mayol-Bracero, O. L., Grassian, V. H., Bertram, T. H., Bertram, A. K., Moffett, B. F., and Franc, G. D.: Sea spray aerosol as a unique source of ice nucleating particles, P. Natl. Acad. Sci. USA, 113, 5797-5803, https://doi.org/10.1073/pnas.1514034112, 2016.

DMT: Single particle imaging, Data analysis user's guide, DOC0223, Rev. A, Tech. Rep., 34 pp., 2009.

Ersoy, O. K.: Diffraction, Fourier optics and imaging, John Wiley \& Sons, Hoboken, New Jersey, USA, 2007.

Field, P. R., Heymsfield, A. J., and Bansemer, A.: Shattering and Particle Interarrival Times Measured by Optical Array Probes in Ice Clouds, J. Atmos. Ocean. Tech., 23, 1357-1371, https://doi.org/10.1175/JTECH1922.1, 2006.

Field, P. R., Lawson, R. P., Brown, P. R. A., Lloyd, G., Westbrook, C., Moisseev, D., Miltenberger, A., Nenes, A., Blyth, A., Choularton, T., Connolly, P., Buehl, J., Crosier, J., Cui, Z., Dearden, C., DeMott, P., Flossmann, A., Heymsfield, A., Huang, Y., Kalesse, H., Kanji, Z. A., Korolev, A., Kirchgaessner, A., Lasher-Trapp, S., Leisner, T., McFarquhar, G., Phillips, V., Stith, J., and Sullivan, S.: Secondary Ice Production: Current State of the Science and Recommendations for the Future, Meteor. Mon., 58, 7.1-7.20, https://doi.org/10.1175/AMSMONOGRAPHS-D16-0014.1, 2017.

Gardiner, B. A. and Hallett, J.: Degradation of incloud forward scattering spectrometer probe measurements in the presence of ice particles, J. Atmos. Ocean. Tech., 2, 171-180, https://doi.org/10.1175/15200426(1985)002<0171:DOICFS>2.0.CO;2, 1985.

Gaskill, J. D.: Linear systems, Fourier transforms, and optics, Wiley, New York, USA, 1978.

Goodman, J. W.: Introduction to Fourier optics, McGraw-Hill, New York, USA, 2nd Edn., 1996.

Gurganus, C. and Lawson, P.: Laboratory and Flight Tests of 2D Imaging Probes: Toward a Better Understanding of Instrument Performance and the Impact on Archived Data, J. Atmos. 
Ocean. Tech., 35, 1533-1553, https://doi.org/10.1175/JTECHD-17-0202.1, 2018.

Hallett, J. and Mossop, S. C.: Production of secondary ice particles during the riming process, Nature, 249, 26-28, https://doi.org/10.1038/249026a0, 1974.

Hayman, M., McMenamin, K. J., and Jensen, J. B.: Response Time Characteristics of the Fast-2D Optical Array Probe Detector Board, J. Atmos. Ocean. Tech., 33, 2569-2583, https://doi.org/10.1175/JTECH-D-16-0062.1, 2016.

Heymsfield, A. J., Schmitt, C., and Bansemer, A.: Ice Cloud Particle Size Distributions and Pressure-Dependent Terminal Velocities from In Situ Observations at Temperatures from $0^{\circ}$ to $-86^{\circ} \mathrm{C}$, J. Atmos. Sci., 70, 4123-4154, https://doi.org/10.1175/JAS-D-120124.1, 2013.

Hirleman, E. D., Holve, D. J., and Hovenac, E. A.: Calibration of single particle sizing velocimeters using photomask reticles, in: 4th International Symposium on Applications of Laser Anemometry to Fluid Mechanics, Lisbon, Portugal, 11-14 July, 6-10, 1988.

Hovenac, E. A.: Use of rotating reticles for calibration of single particle counters, International Congress on Applications of Lasers and Electro-Optics, Arlington, VA, USA, 10-13 November 1986, 58, 129-134, https://doi.org/10.2351/1.5057795, 1986.

Hovenac, E. A. and Hirleman, E. D.: Use of Rotating Pinholes and Reticles for Calibration of Cloud Droplet Instrumentation, J. Atmos. Ocean. Tech., 8, 166-171, https://doi.org/10.1175/15200426(1991)008<0166:UORPAR>2.0.CO;2, 1991.

Hovenac, E. A., Hirleman, E. D., and Ide, R. F.: Calibration and sample volume characterization of PMS optical array probes, in: International Conference on Liquid Atomisation and Spray Systems, Imperial College, London, 8-10 July, 1985.

Joe, P. and List, R.: Testing and performance of twodimensional optical array spectrometers with greyscale, J. Atmos. Ocean. Tech., 4, 139-150, https://doi.org/10.1175/15200426(1987)004<0139:TAPOTD>2.0.CO;2, 1987.

King, W. D.: Air flow and particle trajectories around aircraft fuselages, IV: Orientation of ice crystals, J. Atmos. Ocean. Tech., 3, 433-439, https://doi.org/10.1175/15200426(1986)003<0433:AFAPTA>2.0.CO;2, 1986.

Knollenberg, R. G.: The Optical Array: An Alternative to Scattering or Extinction for Airborne Particle Size Determination, J. Appl. Meteorol., 9, 86-103, https://doi.org/10.1175/15200450(1970)009<0086:TOAAAT>2.0.CO;2, 1970.

Koenig, L. R.: Drop freezing through drop breakup, J. Atmos. Sci., 22, 448-451, https://doi.org/10.1175/15200469(1965)022<0448:DFTDB>2.0.CO;2, 1965.

Korolev, A.: Reconstruction of the Sizes of Spherical Particles from Their Shadow Images, Part I: Theoretical Considerations, J. Atmos. Ocean. Tech., 24, 376-389, https://doi.org/10.1175/JTECH1980.1, 2007.

Korolev, A. and Field, P. R.: Assessment of the performance of the inter-arrival time algorithm to identify ice shattering artifacts in cloud particle probe measurements, Atmos. Meas. Tech., 8, 761777, https://doi.org/10.5194/amt-8-761-2015, 2015.

Korolev, A. and Isaac, G. A.: Shattering during sampling by OAPs and HVPS, Part I: Snow particles, J. Atmos. Ocean. Tech., 22, 528-542, https://doi.org/10.1175/JTECH1720.1, 2005.

Korolev, A. and Sussman, B.: A Technique for Habit Classification of Cloud Particles, J. Atmos. Ocean.
Tech., 17, 1048-1057, https://doi.org/10.1175/1520 0426(2000)017<1048:ATFHCO>2.0.CO;2, 2000.

Korolev, A. V., Kuznetsov, S. V., Makarov, Y. E., and Novikov, V. S.: Evaluation of Measurements of Particle Size and Sample Area from Optical Array Probes, J. Atmos. Ocean. Tech., 8, 514-522, https://doi.org/10.1175/15200426(1991)008<0514:EOMOPS>2.0.CO;2, 1991.

Korolev, A. V., Strapp, J. W., and Isaac, G. A.: Evaluation of the Accuracy of PMS Optical Array Probes, J. Atmos. Ocean. Tech., 15, 708-720, https://doi.org/10.1175/15200426(1998)015<0708:EOTAOP>2.0.CO;2, 1998.

Korolev, A. V., Emery, E. F., Strapp, J. W., Cober, S. G., Isaac, G. A., Wasey, M., and Marcotte, D.: Small Ice Particles in Tropospheric Clouds: Fact or Artifact? Airborne Icing Instrumentation Evaluation Experiment, B. Am. Meteorol. Soc., 92, 967973, https://doi.org/10.1175/2010BAMS3141.1, 2011.

Lawson, R. P.: Effects of ice particles shattering on the 2D-S probe, Atmos. Meas. Tech., 4, 1361-1381, https://doi.org/10.5194/amt4-1361-2011, 2011.

Lawson, R. P., Angus, L. J., and Heymsfield, A. J.: Cloud Particle Measurements in Thunderstorm Anvils and Possible Weather Threat to Aviation, J. Aircraft, 35, 113-121, https://doi.org/10.2514/2.2268, 1998.

Lawson, R. P., O'Connor, D., Zmarzly, P., Weaver, K., Baker, B., Mo, Q., and Jonsson, H.: The 2D-S (Stereo) Probe: Design and Preliminary Tests of a New Airborne, High-Speed, HighResolution Particle Imaging Probe, J. Atmos. Ocean. Techn., 23, 1462-1477, https://doi.org/10.1175/JTECH1927.1, 2006.

Leisner, T., Pander, T., Handmann, P., and Kiselev, A.: Secondary ice processes upon heterogeneous freezing of cloud droplets, 14th Conference on Cloud Physics, Boston, MA, USA, 7-11 July 2014, https://ams.confex.com/ams/14CLOUD14ATRAD/ webprogram/Paper250221.html (last access: 16 April 2019), 2014.

Mason, J., Strapp, W., and Chow, P.: The Ice Particle Threat to Engines in Flight, in: 44th AIAA Aerospace Sciences Meeting and Exhibit, American Institute of Aeronautics and Astronautics, https://doi.org/10.2514/6.2006-206, 2006.

Matsushima, K. and Shimobaba, T.: Band-limited angular spectrum method for numerical simulation of free-space propagation in far and near fields, Opt. Express, 17, 19662-19673, https://doi.org/10.1364/OE.17.019662, 2009.

Matsushima, K., Schimmel, H., and Wyrowski, F.: Fast calculation method for optical diffraction on tilted planes by use of the angular spectrum of plane waves, J. Opt. Soc. Am., 20, 1755-1762, https://doi.org/10.1364/JOSAA.20.001755, 2003.

McFarquhar, G. M., Baumgardner, D., Bansemer, A., Abel, S. J., Crosier, J., French, J., Rosenberg, P., Korolev, A., Schwarzoenboeck, A., Leroy, D., Um, J., Wu, W., Heymsfield, A. J., Twohy, C., Detwiler, A., Field, P., Neumann, A., Cotton, R., Axisa, D., and Dong, J.: 11 - Processing of Ice Cloud In Situ Data Collected by Bulk Water, Scattering, and Imaging Probes: Fundamentals, Uncertainties, and Efforts toward Consistency, Meteor. Mon., 58, 11.1-11.33, https://doi.org/10.1175/AMSMONOGRAPHSD-16-0007.1, 2017a.

McFarquhar, G. M., Baumgardner, D., and Heymsfield, A. J.: 0 - Background and Overview, Meteor. Mon., 58, vix, https://doi.org/10.1175/AMSMONOGRAPHS-D-16-0018.1, 2017b. 
Mitchell, D. L., Rasch, P., Ivanova, D., McFarquhar, G., and Nousiainen, T.: Impact of small ice crystal assumptions on ice sedimentation rates in cirrus clouds and GCM simulations, Geophys. Res. Lett., 35, L09806, https://doi.org/10.1029/2008GL033552, 2008.

Miyamoto, K. and Wolf, E.: Generalization of the Maggi-Rubinowicz theory of the boundary diffraction wave - Part II, J. Opt. Soc. Am., 52, 626-636, https://doi.org/10.1364/JOSA.52.000626, 1962.

Mossop, S. C.: Comparisons between concentration of ice crystals in cloud and the concentration of ice nuclei, Journal de Recherches Atmospheriques, 3, 119-124, 1968.

Noel, V. and Sassen, K.: Study of planar ice crystal orientations in ice clouds from scanning polarization lidar observations, J. Appl. Meteorol., 44, 653-664, https://doi.org/10.1175/JAM2223.1, 2005.

Reuter, A. and Bakan, S.: Improvements of Cloud Particle Sizing with a 2D-Grey Probe, J. Atmos. Ocean. Tech., 15, 1196-1203, https://doi.org/10.1175/15200426(1998)015<1196:IOCPSW>2.0.CO;2, 1998.

SPEC: 2D-S post-processing using 2D-S View Software: User manual, Version 1.1, Tech. Rep., 48 pp., 2011.
Takahashi, T., Nagao, Y., and Kushiyama, Y.: Possible High Ice Particle Production during Graupel-Graupel Collisions, J. Atmos. Sci., 52, 4523-4527, https://doi.org/10.1175/15200469(1995)052<4523:PHIPPD>2.0.CO;2, 1995.

Thompson, B. J.: Diffraction by Opaque and Transparent Particles, Opt. Eng., 2, 43-46, https://doi.org/10.1117/12.7971274, 1964.

Vaillant de Guélis, T.: Simulations of cloud particle diffraction pattern, TIB AV-Portal, https://av.tib.eu/series/627/simulations+of+ cloud+particle+diffraction+pattern, last access: 16 April 2019.

Vaillant de Guélis, T., Shcherbakov, V., and Schwarzenböck, A.: Diffraction patterns from opaque planar objects simulated with Maggi-Rubinowicz method and angular spectrum theory, Opt. Express, 27, 9372-9381, https://doi.org/10.1364/OE.27.009372, 2019.

Welzl, E.: Smallest enclosing disks (balls and ellipsoids), in: New Results and New Trends in Computer Science, edited by: Maurer, H., Lecture Notes in Computer Science, Springer Berlin Heidelberg, 359-370, 1991.

Wu, W. and McFarquhar, G. M.: On the Impacts of Different Definitions of Maximum Dimension for Nonspherical Particles Recorded by 2D Imaging Probes, J. Atmos. Ocean. Tech., 33, 1057-1072, https://doi.org/10.1175/JTECH-D-15-0177.1, 2016. 